\title{
D-Penicillamine and L-Cysteine Derived Thiazolidine Catalysts: An Efficient Approach to Both Enantiomers of Secondary Alcohols
}

M. Elisa Silva Serra*, Dora Costa, Dina Murtinho, Nélia C. T. Tavares, Teresa M. V. D. Pinho e Melo

CQC and Department of Chemistry, University of Coimbra, 3004-535 Coimbra, Portugal

e-mail: melisa@ci.uc.pt; tel: +0035139854480

Graphical abstract

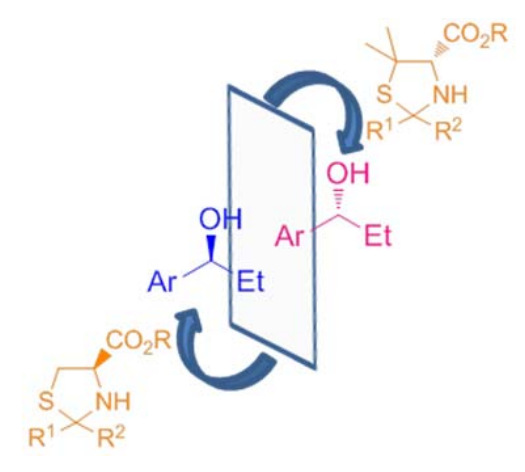




\title{
D-Penicillamine and L-Cysteine Derived Thiazolidine Catalysts: An Efficient Approach to Both Enantiomers of Secondary Alcohols
}

\author{
M. Elisa Silva Serra*, Dora Costa, Dina Murtinho, Nélia C. T. Tavares, Teresa M. V. D. Pinho e \\ Melo \\ CQC and Department of Chemistry, University of Coimbra, 3004-535 Coimbra, Portugal \\ e-mail: melisa@ci.uc.pt; tel: 0035139854480
}

\begin{abstract}
D-Penicillamine derived thiazolidine ligands were prepared in a two-step synthetic sequence and used in the enantioselective alkylation of a variety of aromatic aldehydes with diethylzinc at room temperature. Excellent ee, up to $>99 \%$, and nearly complete conversions were observed. Structurally analogous L-cysteine derived thiazolidine ligands were also synthesized and tested for comparative purposes, resulting in very good, albeit slightly lower selectivities, up to $89 \%$. The combined use of these two types of thiazolidines constitutes a very interesting strategy for synthesizing both $(S)$ and $(R)$ enantiomers of chiral secondary alcohols, thus leading the way to a myriad of useful optically active products with opposite absolute configurations.
\end{abstract}

Keywords: Asymmetric catalysis, Alkylation, Thiazolidine, L-Cysteine, D-Penicillamine

\section{Introduction}

Synthetic procedures for efficiently obtaining chiral secondary alcohols are of major importance due to the vast application of these compounds in fine chemistry, pharmaceuticals, perfumes, herbicides, pesticides and because these alcohols incorporate many structures with biological activity. There is also the purely synthetic facet, since the hydroxyl group is an excellent precursor for many other functional groups, being very useful in organic synthesis for obtaining a wide variety of chiral compounds. The enantioselective alkylation of aromatic aldehydes with diethylzinc in the presence of chiral ligands is a versatile and extremely valuable synthetic strategy for obtaining optically active secondary alcohols. Besides creating a new chiral center from the carbonyl carbon, the reaction allows for the elongation of the carbon chain in the alcohol relatively to the parent aldehyde. ${ }^{1-7}$

Many types of chiral ligands have been used in this process, namely, diamines and their derivatives, diols and amino alcohols, among others giving products with high enantiomeric excesses ${ }^{8,9}$ Ligands with cyclic or bicyclic structures are especially good candidates as chiral ligands due to their rigid backbone structures. ${ }^{10-17}$ Chiral 1,3-thiazolidine-4-carboxylates derived from the naturally occurring amino acid L-cysteine have been sparingly used for inducing chirality in the enantioselective alkylation of aldehydes with diethylzinc, originating secondary alcohols with good to excellent enantiomeric excesses. ${ }^{18-23}$ These ligands are easily obtained in a simple two-step synthetic sequence involving the esterification of L-cysteine followed by condensation with a 
carbonyl compound, aldehyde or ketone, to give a rigid five-membered heterocycle 1 (Scheme 1). To the best of our knowledge, there is no reference of the use of structurally identical D-penicillamine derived thiazolidines 2 (Scheme 1) in enantioselective alkylation reactions. These thiazolidines, easily obtained by a simple process (similar to that already described), esterification of D-penicillamine followed by condensation with the carbonyl compound, could bring singular advantages to many catalytic processes.

The fact that L-cysteine has a chiral center with $(R)$ absolute configuration, while D-penicillamine's chiral center has $(S)$ absolute configuration, can allow attaining product alcohols with both $(R)$ and $(S)$ absolute configurations when one or the other thiazolidine derivative is used, thus leading the way to a myriad of useful optically active products with opposite absolute configurations.

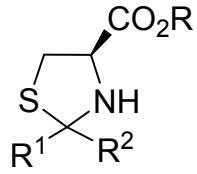

1

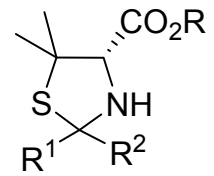

2

Scheme 1

On the other hand, the two C5 methyl groups in D-penicillamine derived $\mathbf{2}$ may also have an influence on the ee of the products formed in the alkylation reaction. The increased steric crowding, when combined with the C2 substituents, may be either beneficial or detrimental.

In continuation of our studies on the enantioselective alkylation of aldehydes, ${ }^{24-28}$ we undertook the synthesis of D-penicillamine derived thiazolidines $\mathbf{2 a - c}$ and subsequently tested them in the enantioselective alkylation of benzaldehyde with diethylzinc. Simultaneously, we synthesized structurally analogous L-cysteinederived thiazolidines 1a-c in order to analyze the effect of the chiral center and of the steric hindrance on the selectivity of the alkylation products.

\section{Results and Discussion}

D-Penicillamine was esterified with thionyl chloride and methanol, under reflux according to a previously described procedure. ${ }^{29}$ In order to prepare thiazolidines $\mathbf{2 b}, \mathbf{c}$ and $\mathbf{1 b}, \mathbf{c}$ the D-penicillamine and L-cysteine methyl ester hydrochlorides were treated with triethylamine and then reacted with acetone or 3-pentanone in the presence of a catalytic amount of TFA, under cyclohexane reflux for 18-24 h. ${ }^{23}$ Thiazolidines 1a and $\mathbf{2 a}$ were obtained by reaction of the ester hydrochlorides with a formaldehyde solution in the presence of $\mathrm{KHCO}_{3}$, ethanol/water (3:4) at room temperature overnight (Scheme 2). ${ }^{30}$

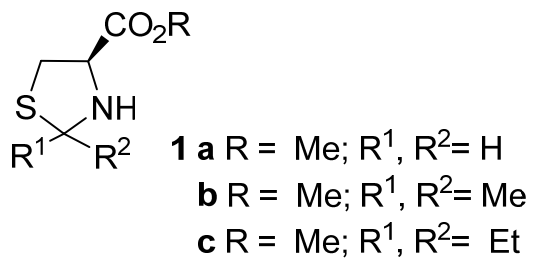

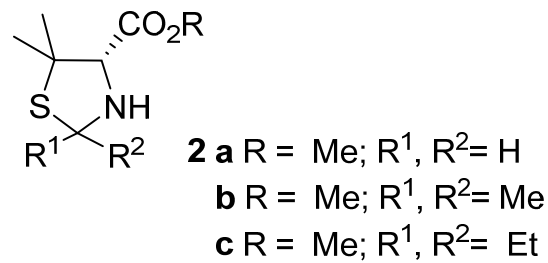

Scheme 2 
Using our previously established reaction conditions, ${ }^{24}$ we carried out the alkylation of benzaldehyde with diethylzinc in cyclohexane, in an inert atmosphere and at room temperature. The results are presented in Table 1.

\begin{tabular}{|c|c|c|c|c|}
\hline \multirow[b]{2}{*}{ Entry } & \multicolumn{2}{|c|}{$\mathrm{H}+\mathrm{Et}_{2} \mathrm{Zn}$} & $\frac{\text { chiral ligand }}{\text { cyclohexane, } \mathrm{rt} \text {, }}$ & \\
\hline & Ligand & $\begin{array}{c}\text { Conversion } \\
(\%)^{\mathrm{b}}\end{array}$ & $\begin{array}{c}\text { 1-phenyl-1-propanol } \\
(\%)^{b}\end{array}$ & $\begin{array}{c}e e \\
(\%)^{\mathrm{c}}\end{array}$ \\
\hline 1 & $1 a$ & 99 & 96 & $67(S)$ \\
\hline 2 & $1 b$ & 95 & 96 & $83(S)$ \\
\hline 3 & $1 c$ & 99 & 99 & $89(S)$ \\
\hline 4 & $2 a$ & 99 & 98 & $93(R)$ \\
\hline 5 & $2 b$ & 99 & 99 & $92(R)$ \\
\hline 6 & $2 c$ & 99 & 99 & $94(R)$ \\
\hline \multicolumn{5}{|c|}{$\begin{array}{l}{ }^{2} \text { Reactions conditions: cyclohexane }(4 \mathrm{~mL}) \text {, chiral ligand }(0.15 \\
\mathrm{mmol}) \text {, benzaldehyde }(1 \mathrm{mmol}) \text {, diethylzinc solution } 1 \mathrm{M} \text { in hexane } \\
(2 \mathrm{mmol}), 24 \mathrm{~h} \text {, room temperature. }{ }^{\mathrm{b}} \text { Determined by GC. } \\
\text { 'Determined by GC on a chiral column; the major enantiomer is } \\
\text { indicated in parenthesis. }\end{array}$} \\
\hline
\end{tabular}

All of the thiazolidines tested gave nearly complete conversion of benzaldehyde to the corresponding secondary alcohol. Thiazolidines 2 gave products with excellent ee (92-94\%), while thiazolidines 1 gave good ee $(67-89 \%)$, indicating that the former are much more efficient chiral inducers in these reactions, under our optimized conditions.

The results observed with $\mathbf{2}$ indicate that the most important steric factor here seems to be the two C 5 methyl groups, while the $\mathrm{C} 2$ substituents do not appear to significantly contribute to the chiral induction by these thiazolidines. On the other hand, the $\mathrm{C} 2$ substituents on thiazolidines 1 do have a significant effect on the chiral induction capacity of these ligands. 1c, the most sterically encumbered ligand, with two ethyl groups at C2, gave 1-phenyl-1-propanol with the highest ee of this series, $89 \%$.

As was initially expected, due to the opposite stereochemistry of the chiral C4 of the ligands, the two series originated products with opposite absolute configuration, creating a very useful system for obtaining both enantiomers of secondary alcohols.

Proline and pyrrole esters are referred to present bidentate coordination, namely, through the carbonyl oxygen and the ring nitrogen atom. ${ }^{31-33}$ It is believed that thiazolidine esters also coordinate in a similar bidentate manner. We decided to evaluate the effect on the selectivity of the process, of the presence of an additional coordinating atom on the thiazolidine, which could open the way to new interesting derivatives. For this study we synthesized L-cysteine derived thiazolidines 3a-3c. For the same purpose, we also synthesized the corresponding D-penicillamine derivatives 4a-c (Scheme 3). These aldehyde-derived thiazolidines are formed 
as diastereoisomeric mixtures with respect to $\mathrm{C} 2$. In solution these diastereoisomers interconvert through a mechanism involving opening of the thiazolidine ring. ${ }^{34,35}$

It has been observed that the existence of the two diastereoisomers, in itself, does not affect the selectivity in enantioselective reactions using this type of ligands. This has been explained as resulting from different characteristics, namely, significantly different rates of reaction of the two diastereoisomeric catalysts or lack of coordination of one of the diastereoisomers. ${ }^{21,36,37}$
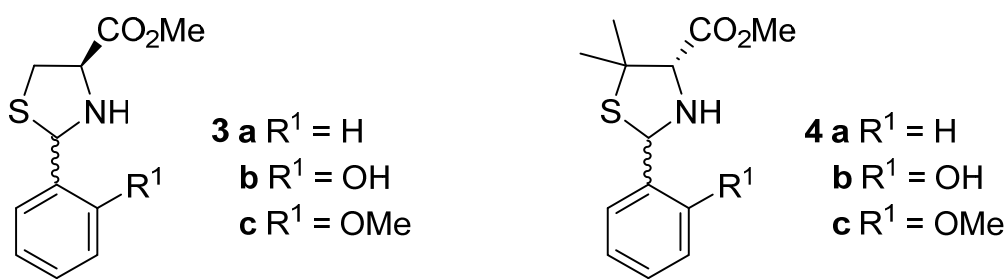

\section{Scheme 3}

The ethyl ester of $\mathbf{3} \mathbf{a}$ has been previously used in the enantioselective alkylation of benzaldehyde, giving a product with $80 \%$ ee. ${ }^{21}$ We synthesized the methyl ester (Table 2, ee $75 \%$ ) for comparative purposes, since all thiazolidines used in our studies are methyl esters. The tridentate ligand $\mathbf{3 b}$ was synthesized by condensation of the cysteine methyl ester hydrochloride with salicylaldehyde. ${ }^{38}$ In the alkylation of benzaldehyde with $\mathrm{ZnEt}_{2}$, this ligand led to moderate conversion and low ee, 10\% (Table 2, entry 2). This clearly demonstrates the negative effect of the presence of the hydroxyl group. In order to clarify whether this result is due to coordination or simply to additional steric volume close to the coordinating atoms, we synthesized yet another derivative 3c, with a methoxy instead of a hydroxyl group. The higher conversion and ee observed with this ligand (Table 2, entry 3 ) seem to indicate that the low performance of $3 \mathbf{b}$ may be due to an unfavorable tridentate coordination. An alternative mode of bidentate coordination to the zinc, involving the nitrogen and the hydroxyl instead of the ester, is also plausible.

Table 2. Enantioselective alkylation of benzaldehyde in the presence of chiral thiazolidines 3-4.

\begin{tabular}{ccccc}
\hline Entry & Ligand & $\begin{array}{c}\text { Conversion } \\
(\%)^{\mathrm{b}}\end{array}$ & $\begin{array}{c}\text { 1-phenyl-1-propanol } \\
(\%)^{\mathrm{b}}\end{array}$ & $\begin{array}{c}\text { ee } \\
(\%)^{\mathrm{c}}\end{array}$ \\
\hline 1 & $\mathbf{3 a}$ & 92 & 98 & $75(S)$ \\
2 & 3b & 77 & 78 & $10(S)$ \\
3 & $\mathbf{3 c}$ & 91 & 95 & $57(S)$ \\
4 & $\mathbf{4 a}$ & 95 & 97 & $87(R)$ \\
5 & $\mathbf{4 b}$ & 92 & 90 & $11(R)$ \\
6 & 4c & $>99$ & 99 & $84(R)$ \\
\hline
\end{tabular}

${ }^{a}$ Reactions conditions: cyclohexane $(4 \mathrm{~mL})$, chiral ligand $(0.15$ $\mathrm{mmol})$, benzaldehyde $(1 \mathrm{mmol})$, diethylzinc solution $1 \mathrm{M}$ in hexane (2 mmol), $24 \mathrm{~h}$, room temperature. 'Determined by GC. 'Determined by GC on a chiral column; the major enantiomer is indicated in parenthesis. 
We additionally synthesized the analogous penicillamine derived ligands 4a-c. A similar trend was observed in the enantioselective alkylation of benzaldehyde with these ligands (Table 2, entries 4-6). Once again the hydroxyl containing ligand gave the product alcohol with low ee, while the methoxy derivative $4 \mathrm{c}$ gave the product with $85 \%$ ee. The results observed with $\mathbf{3}$ and $\mathbf{4}$ seem to indicate that coordination of the thiazolidines to the zinc atom by the nitrogen atom and ester group favors chiral induction.

Using D-penicillamine derived thiazolidine $\mathbf{2 a}$, we carried out the alkylation of several other aromatic aldehydes with $\mathrm{ZnEt}_{2}$, in order to assess the scope of these ligands. The results of this study are presented in Table 3. All aldehydes suffered complete conversion to the product alcohol, except for $p$-anisaldehyde (97\%). The ee of the chiral alcohols, 86 to $>99 \%$, prove the excellent performance of the ligand, covering a range of aromatic phenyl substrates with both electron-donating and electron-withdrawing substituents, as well as naphthaldehyde.

\begin{tabular}{cccc}
\multicolumn{3}{l}{$\begin{array}{l}\text { Table 3. Enantioselective alkylation of aromatic aldehydes in } \\
\text { the presence of chiral thiazolidine } \mathbf{2 a}^{{ }^{a}}\end{array}$} \\
\hline Entry & Aldehyde & $\begin{array}{c}\text { Conversion } \\
(\%)^{b}\end{array}$ & $\begin{array}{c}e e \\
(\%)^{\mathrm{b}}\end{array}$ \\
\hline 1 & benzaldehyde & $>99$ & $95(R)$ \\
2 & o-methylbenzaldehyde & $>99$ & $89(R)$ \\
3 & $p$-methylbenzaldehyde & $>99$ & $95(R)$ \\
4 & o-anisaldehyde & $>99$ & $98(R)$ \\
5 & $m$-anisaldehyde & $>99$ & $>99(R)$ \\
6 & $p$-anisaldehyde & 97 & $>99(R)$ \\
7 & o-chlorobenzaldehyde & $>99$ & $86(R)$ \\
8 & $p$-chlorobenzaldehyde & $>99$ & $91(R)$ \\
9 & 1-naphthaldehyde & 99 & $97(R)$
\end{tabular}

${ }^{\mathrm{a}}$ Reactions conditions: cyclohexane $(4 \mathrm{~mL})$, chiral ligand $(0.15 \mathrm{mmol})$, aldehyde $(1 \mathrm{mmol})$, diethylzinc solution $1 \mathrm{M}$ in hexane $(2 \mathrm{mmol}), 24 \mathrm{~h}$, room temperature. ${ }^{\mathrm{b}}$ Determined by GC. 'Determined by GC on a chiral column; the major enantiomer is indicated in parenthesis.

We tested heteroaromatic furfural and aliphatic cinnamaldehyde, phenylacetaldehyde and octanal as substrates as well, in the presence of $\mathbf{2 a}$, in order to further assess the scope of our ligands (Table 4). At room temperature, almost complete conversions were observed except for phenylacetaldehyde and ee varied from $24 \%$ to $80 \%$, the best result being obtained in the alkylation of octanal. Considering the high activity of the catalyst, we decided to lower the temperature to $0^{\circ} \mathrm{C}$ (Table 4 , entries $\left.2,3,5\right)$ and found that there was no significant change in yield and a small increase in the ee of the products. A further decrease in temperature to $-10^{\circ} \mathrm{C}$ in the case of cinnamaldehyde also had no effect on either conversion or ee. 
Table 4. Enantioselective alkylation of cinnamaldehyde and furfural in the presence of chiral thiazolidine $2 \mathbf{a}^{\mathrm{a}}$

\begin{tabular}{|c|c|c|c|c|}
\hline Entry & Aldehyde & Temperature & $\begin{array}{c}\text { Conversion } \\
(\%)^{\mathrm{b}}\end{array}$ & $\begin{array}{c}\text { ee } \\
(\%)^{c}\end{array}$ \\
\hline 1 & \multirow{3}{*}{$\approx \mathrm{CHO}$} & $\mathrm{rt}$ & 99 & 47 \\
\hline 2 & & $0^{\circ} \mathrm{C}$ & $>99$ & 56 \\
\hline 3 & & $-10^{\circ} \mathrm{C}$ & 96 & 56 \\
\hline 4 & \multirow{2}{*}{$\| \mathrm{O}\rangle_{\mathrm{CHO}}$} & $\mathrm{rt}$ & $>99$ & 56 \\
\hline 5 & & $0^{\circ} \mathrm{C}$ & $>99$ & 60 \\
\hline 6 & $\mathrm{CHO}$ & $\mathrm{rt}$ & 30 & 24 \\
\hline 7 & $\sim \mathrm{CHO}$ & $\mathrm{rt}$ & 99 & $80^{d}$ \\
\hline \multicolumn{5}{|c|}{$\begin{array}{l}\text { Reactions conditions: cyclohexane }(4 \mathrm{~mL}) \text {, chiral ligand }(0.15 \mathrm{mmol}) \text {, } \\
\text { aldehyde }(1 \mathrm{mmol}) \text {, diethylzinc solution } 1 \mathrm{M} \text { in hexane }(2 \mathrm{mmol}), 24 \mathrm{~h} \text {. } \\
\text { b Determined by GC. 'Determined by GC on a chiral column. 'Determined } \\
\text { by polarimetry. }\end{array}$} \\
\hline
\end{tabular}

\section{Conclusions}

Using a simple two-step synthetic sequence three D-penicillamine derived chiral thiazolidine ligands were prepared through condensation with ketones and aldehydes. Using our most selective ligand, products with excellent selectivity, up to $>99 \%$ ee of the $(R)$ enantiomer, were obtained in the alkylation of aromatic aldehydes with diethylzinc at room temperature. When the ligand was used in the enantioselective alkylation of hetero- and non-aromatic aldehydes, ee of up to $80 \%$ were observed, which are interesting values for these types of substrates.

Analogous L-cysteine derived thiazolidines, also synthesized and tested in the alkylation of benzaldehyde, giving up to $89 \%$ ee of the $(S)$ enantiomer, demonstrate that it is possible to efficiently and selectively obtain both enantiomers of chiral secondary alcohols. The combined use of both D-penicillamine and L-cysteine derived thiazolidines constitutes a very interesting strategy that can lead to the synthesis of a great variety of chiral compounds having opposite absolute configurations, with potential applications in fine chemistry.

\section{Experimental Section}

\section{General}

Commercially available compounds were used without further purification. All solvents were dried prior to use following standard procedures. Diethylzinc (Aldrich) was used as a $1 \mathrm{M}$ solution in hexane. Benzaldehyde was distilled prior to use and stored over $4 \AA$ molecular sieves. Melting points were determined using a FALC melting point apparatus (open capillary method). Optical rotations were measured with an Optical Activity AA5 polarimeter. NMR spectra were recorded at room temperature on a Bruker Avance III $400 \mathrm{MHz}(100 \mathrm{MHz}$ for ${ }^{13} \mathrm{C}$ ). TMS was used as the internal standard and chemical shifts are given in ppm. Infrared spectra were recorded on a Thermo Scientific Nicolet 6700 FTIR. High-resolution mass spectra (HRMS) were obtained on a TOF VG Autospect M spectrometer with electrospray ionization (ESI). 
Alkylation reactions were carried out in an inert atmosphere using standard Schlenk-type techniques.

Enantiomeric excesses were determined by using a chiral $y$-cyclodextrin capillary column (FS-Lipodex-E, 25 m, 0.25 i.d.) from Machery-Nagel using hydrogen as carrier gas, on an Agilant 7820 instrument (for the phenylacetadehyde product, a $\beta$-cyclodextrin capillary column was used). The configuration of the major enantiomers was determined by comparison of the retention times with reported values and by determining the sign of the optical rotation of the isolated reactions. The ee of 3-decanol was determined by polarimetry $\left([\alpha]_{D}^{21}=+9.95(c 3.96\right.$, pentane $){ }^{39}$

Thiazolidines $1 a^{28} \mathbf{1} b^{29} 1 c^{13} 3 a^{23} 3 b^{38} 4 a^{40,41}$ were prepared according to adapted literature procedures and presented spectroscopic data in agreement with that described. D-Penicillamine methyl ester hydrochloride was prepared according to a described procedure and used directly. ${ }^{29}$

\section{General procedure for the synthesis of thiazolidines $\mathbf{2 b}, \mathbf{2 c}$ :}

To the (S)-penicillamine methyl ester hydrochloride $(3 \mathrm{mmol}, 0.60 \mathrm{~g})$ in dry cyclohexane $(10 \mathrm{~mL})$, triethylamine ( $3 \mathrm{mmol}, 0.42 \mathrm{~mL}$ ) was added, followed by the ketone $(2.7 \mathrm{mmol}$ ) and 2-3 drops of TFA. The reaction was refluxed for $24 \mathrm{~h}$. The resulting suspension was filtered, the residue was washed with ether and the combined filtrates were evaporated to give the thiazolidine, which was purified as described below.

(S)-methyl 2,2,5,5-tetramethylthiazolidine-4-carboxylate (2b): The product was purified by alumina column chromatography using ethyl acetate:hexane (1:2) as eluent to give a white solid, mp: $34-36{ }^{\circ} \mathrm{C}$. Yield: $55 \%$. [ $\alpha$ ] ${ }_{D}^{20}=+122\left(c 1.06, \mathrm{CH}_{2} \mathrm{Cl}_{2}\right)$. IR $\left(\mathrm{KBr}, \mathrm{cm}^{-1}\right): 2966,2920,1743,1456,1439,1379,1369,1342,1279,1225$, 1196, 1180, 1144, 1115, 1028, 1007. ${ }^{1} \mathrm{H}$ NMR $\left(\mathrm{CDCl}_{3}\right): \delta=1.21$ (s, 3H); $1.54(\mathrm{~s}, 3 \mathrm{H}) ; 1.62(\mathrm{~s}, 3 \mathrm{H}) ; 1.66(\mathrm{~s}$, $3 \mathrm{H}$ ); 3.76 (s, 3H); 4.02 (s, $1 \mathrm{H}$ ); 4.87 (bs, $1 \mathrm{H}$ ); ${ }^{13} \mathrm{C}$ NMR: $\delta=27.9 ; 28.9 ; 32.0 ; 33.4 ; 52.1 ; 61.1 ; 72.7 ; 73.0$; 170.0. HRMS (ESI): calcd. for $\mathrm{C}_{9} \mathrm{H}_{18} \mathrm{NO}_{2} \mathrm{~S}[\mathrm{M}+\mathrm{H}]^{+}$204.1053; found [M+H] $]^{+} 204.1058$.

(S)-methyl 2,2-diethyl-5,5-dimethylthiazolidine-4-carboxylate (2c): The product was purified by alumina column chromatography using an ethyl acetate:hexane gradient as eluent (1:2 to ethyl acetate) to give a colorless oil. Yield: $35 \%$. [ $\alpha]_{D}^{20}=+83\left(c 0.67, \mathrm{CH}_{2} \mathrm{Cl}_{2}\right) . \mathrm{IR}\left(\mathrm{KBr}, \mathrm{cm}^{-1}\right): 2966,2931,2879,1745,1456,1435$, 1367, 1338, 1321, 1261, 1219, 1196, 1173, 1124, 1107. ${ }^{1} \mathrm{H}$ NMR $\left(\mathrm{CDCl}_{3}\right): \delta=0.90$ (t, J=7.4 Hz); 1.01 (t, J=7.4 $\mathrm{Hz}$ ); 1.19 (s, 3H); 1.60 (s, 3H); 1.71-1.93 (m, 4H); 3.04 (bs, $1 \mathrm{H}) ; 3.76(\mathrm{~s}, 3 \mathrm{H}) ; 3.86(\mathrm{~s}, 1 \mathrm{H}) .{ }^{13} \mathrm{C} \mathrm{NMR:} \delta=9.5$; 9.9; $27.9 ; 28.7 ; 32.8 ; 34.9 ; 52.0 ; 58.9 ; 72.7 ; 81.6 ; 170.3$. HRMS (ESI): calcd. for $\mathrm{C}_{11} \mathrm{H}_{22} \mathrm{NO}_{2} \mathrm{~S}[\mathrm{M}+\mathrm{H}]^{+}$ 232.1366; found $[\mathrm{M}+\mathrm{H}]^{+} 232.1362$.

\section{General procedure for the synthesis of thiazolidines 1a, 2a:}

To the penicillamine or cysteine methyl ester hydrochloride $(1.5 \mathrm{mmol}, 0.30 \mathrm{~g})$ in ethanol/water $(3: 4),(7 \mathrm{~mL})$ $\mathrm{KHCO}_{3}(1.5 \mathrm{mmol}, 0.15 \mathrm{~g})$ was added, followed by a $37 \%$ formaldehyde solution $(1.35 \mathrm{mmol}, 0.11 \mathrm{~mL})$. The reaction was stirred at room temperature until complete. Water $(10 \mathrm{~mL})$ was added and the mixture was extracted three times with dichloromethane. The combined organic phases were dried over anhydrous sodium sulfate, filtered and evaporated to give the thiazolidine, which was purified as described below. 


\section{General procedure for the synthesis of thiazolidines 4a-c:}

To the penicillamine or cysteine methyl ester hydrochloride $(1.5 \mathrm{mmol}, 0.30 \mathrm{~g})$ in ethanol/water $(3: 4),(7 \mathrm{~mL})$ $\mathrm{NEt}_{3}(1.5 \mathrm{mmol}, 0.24 \mathrm{~mL})$ was added, followed by the aldehyde $(1.5 \mathrm{mmol})$. The reaction was stirred at room temperature until complete. Water $(10 \mathrm{~mL})$ was added and the mixture was extracted three times with dichloromethane. The combined organic phases were dried over anhydrous sodium sulfate, filtered and evaporated to give the thiazolidine, which was purified as described below.

(S)-methyl 5,5-dimethylthiazolidine-4-carboxylate (2a): The reaction was complete after $18 \mathrm{~h}$. The product was purified by alumina column chromatography using ethyl acetate:hexane (1:2) as eluent to give a low

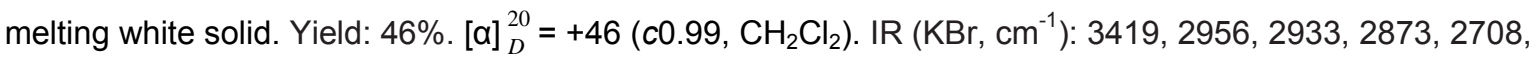
2542, 1747, 1456, 1441, 1396, 1375, 1311, 1246. ${ }^{1} \mathrm{H}$ NMR $\left(\mathrm{CDCl}_{3}\right): \delta=1.21$ (s, $\left.3 \mathrm{H}\right) ; 1.65$ (s, $\left.3 \mathrm{H}\right) ; 3.50$ (s, $1 \mathrm{H}) ; 3.77$ (s, 3H); 4.27 (dd, J= $10 \mathrm{~Hz}, 50 \mathrm{~Hz}, 2 \mathrm{H}) .{ }^{13} \mathrm{C}$ NMR: $\delta=27.9 ; 29.1 ; 52.1 ; 52.3 ; 57.8 ; 74.6 ; 170.1$. HRMS (ESI): calcd. for $\mathrm{C}_{7} \mathrm{H}_{14} \mathrm{NO}_{2} \mathrm{~S}[\mathrm{M}+\mathrm{H}]^{+}$176.0740; found $[\mathrm{M}+\mathrm{H}]^{+} 176.0739$.

(S)-methyl 2-(2-hydroxyphenyl)-5,5-dimethyl-1,3-thiazolidine-4-carboxylate (4b): The reaction was complete after $48 \mathrm{~h}$. The product (a mixture of diastereoisomers) was purified by silica gel chromatography, using ethyl acetate as eluent, and obtained as a dark orange oil, with quantitative yield. $[\alpha]_{D}^{20}=+174(c 1.15$, $\left.\mathrm{CH}_{2} \mathrm{Cl}_{2}\right)$. IR (KBr, cm$\left.{ }^{-1}\right): 3288,3048,2964,2928,2867,1735,1719,1707,1624,1618,1587,1578,1487$, 1457, 1437, 1388, 1368, 1320, 1275, 1254, 1210, 1184, 1126, 1098, 1033, 1015, 999, 927, 875, 850, 751. ${ }^{1} \mathrm{H}$ $\operatorname{NMR}\left(\mathrm{CDCl}_{3}\right): \delta=1.32,1.38(\mathrm{~s}, 3 \mathrm{H}) ; 1.61,1.73(\mathrm{~s}, 3 \mathrm{H}) ; 2.17(\mathrm{~s}, 1 \mathrm{H}) ; 3.75,3.77(\mathrm{~s}, 1 \mathrm{H}) ; 3.79,3.81(\mathrm{~s}, 3 \mathrm{H})$; 5.70, $6.00(\mathrm{~s}, 1 \mathrm{H}) ; 6.80-6.92(\mathrm{~m}, 2 \mathrm{H}) ; 7.14-7.26(\mathrm{~m}, 2 \mathrm{H}) .{ }^{13} \mathrm{C}$ NMR: $\delta=27.1,28.2,28.8,29.9,52.3,52.5,57.2$, 58.0, 66.9, 71.5, 73.4, 117.1, 117.3, 119.4, 119.9, 122.0, 123.2, 123.3, 128.7, 129.4, 130.2, 155.9, 156, 169.3, 169.7. HRMS (ESI): calcd. for $\mathrm{C}_{13} \mathrm{H}_{18} \mathrm{NO}_{3} \mathrm{~S}[\mathrm{M}+\mathrm{H}]^{+}$268.1002; found $[\mathrm{M}+\mathrm{H}]^{+} 268.0997$.

(S)-methyl 2-(2-methoxyphenyl)-5,5-dimethyl-1,3-thiazolidine-4-carboxylate (4c): The reaction was complete after 6 days. The product (a mixture of diastereoisomers) was purified by silica gel chromatography, using ethyl acetate:hexane (1:5) as eluent, giving a light yellow oil, with quantitative yield. $[\alpha]_{D}^{20}=+100(c 1$, $\left.\mathrm{CH}_{2} \mathrm{Cl}_{2}\right)$. IR $\left(\mathrm{KBr}, \mathrm{cm}^{-1}\right)$ : 3338, 2955, 2925, 2837, 1735, 1719, 1600, 1588, 1488, 1458, 1437, 1434, 1367, 1323, 1289, 1260, 1241, 1202, 1183, 1157, 1122, 1099, 1048, 1023, 1000, 929, 841, 778, 751, 669. ${ }^{1} \mathrm{H}$ NMR $\left(\mathrm{CDCl}_{3}\right): \delta=1.30,1.34$ (s, 3H); 1.57, 1.71 (s, 3H); 3.67, 3.75 (s, 1H); 3.79, 3.80 (s, 3H); 3.84, 3.87 (s, 3H); $5.97,6.00,6.01(\mathrm{~s}, 1 \mathrm{H}) ; 6.83-6.99(\mathrm{~m}, 2 \mathrm{H}) ; 7.19-7.31(\mathrm{~m}, 1 \mathrm{H}) ; 7.50-7.55(\mathrm{~m}, 1 \mathrm{H}) .{ }^{13} \mathrm{C} \mathrm{NMR:} \delta=27.3,27.4$, 28.4, 29.1, 52.0, 52.1, 55.3, 55.6, 57.9, 59.091 63.1, 65.2, 73.2, 74.8, 110.4, 111.1, 120.4, 120.8, 124.9, 126.4, 128.0, 128.2, 129.6, 131.9, 156.4, 157.3, 169.9, 170.3. HRMS (ESI): calcd. for $\mathrm{C}_{14} \mathrm{H}_{20} \mathrm{NO}_{3} \mathrm{~S}[\mathrm{M}+\mathrm{H}]^{+}$ 282.1158; found $[\mathrm{M}+\mathrm{H}]^{+} 282.1154$. 


\section{General procedure for the synthesis of thiazolidines 1b, 1c, 3c:}

To $(R)$-cysteine methyl ester hydrochloride $(25 \mathrm{mmol}, 4.29 \mathrm{~g})$ in dry cyclohexane $(50 \mathrm{~mL})$, triethylamine $(25$ $\mathrm{mmol}, 3.49 \mathrm{~mL})$ was added, followed by the aldehyde or ketone $(22.5 \mathrm{mmol})$ and 2-3 drops of TFA. The reaction was refluxed for $24 \mathrm{~h}$. The resulting suspension was filtered, the residue was washed with ether and the combined filtrates were evaporated to give the thiazolidine, which was purified as described below.

(R)-methyl 2-(2-methoxyphenyl)thiazolidine-4-carboxylate (3c): The product (a mixture of diastereoisomers) was purified by silica gel column chromatography using ethyl acetate:hexane (1:2) as eluent to give a pale yellow oil. Yield: $77 \%$. [ $]_{D}^{20}=-120\left(c 1.29, \mathrm{CH}_{2} \mathrm{Cl}_{2}\right)$. IR $\left(\mathrm{KBr}, \mathrm{cm}^{-1}\right): 2951,2837,1743$, 1601, 1587, 1489, 1464, 1437, 1362, 1327, 1296, 1267, 1248, 1203, 1171, 1161, 1122, 1107, 1088, 1049, 1026, 831, 793, 756. ${ }^{1} \mathrm{H}$ NMR $\left(\mathrm{CDCl}_{3}\right): \delta=3.03-3.24(\mathrm{~m}, 1 \mathrm{H}) ; 3.40-3.45(\mathrm{~m}, 1 \mathrm{H}) ; 3.81(\mathrm{~s}, 3 \mathrm{H}) ; 3.87,3.88(\mathrm{~s}$, $3 \mathrm{H}) ; 3.95$ (bs, $1 \mathrm{H}) ; 5.58,6.01(\mathrm{~s}, 1 \mathrm{H}) ; 6.86-7.00(\mathrm{~m}, 2 \mathrm{H}) ; 7.24-7.42(\mathrm{~m}, 2 \mathrm{H}) ; 7.43-7.51(\mathrm{~m}, 2 \mathrm{H}) .{ }^{13} \mathrm{C} \mathrm{NMR:} \delta=$ 37.7, 39.0, 52.5, 52.6, 55.5, 55.7, 64.9, 65.7, 65.9, 67.7, 110.7, 111.1, 120.5, 120.8, 125.8, 126.0, 127.8, 128.7, 129.7, 130.0. HRMS (ESI): calcd. for $\mathrm{C}_{12} \mathrm{H}_{16} \mathrm{NO}_{3} \mathrm{~S}[\mathrm{M}+\mathrm{H}]^{+}$254.0845; found [M+H] 254.0846 .

\section{General procedure for enantioselective alkylations}

To the chiral ligand $(0.15 \mathrm{mmol})$ and aldehyde $(1 \mathrm{mmol})$ in an inert atmosphere, $4 \mathrm{~mL}$ of dry cyclohexane were added. The temperature of the reaction mixture was lowered to $0^{\circ} \mathrm{C}$ and diethylzinc $(2 \mathrm{mmol}, 2 \mathrm{~mL}$, as a $1 \mathrm{M}$ hexane solution) was added. The reaction was stirred $10 \mathrm{~min}$ at $0{ }^{\circ} \mathrm{C}$ and then for $24 \mathrm{~h}$ at the required temperature. Subsequently, a saturated ammonium chloride solution ( $1 \mathrm{~mL}$ ) was added, followed by $2 \mathrm{M} \mathrm{HCl}$ $(1 \mathrm{~mL})$ and the reaction mixture was extracted with diethyl ether. The joint organic phases were washed with water and brine and dried over anhydrous sodium sulfate. The resulting solution was analyzed by $\mathrm{GC}$ on a chiral $\gamma$-cyclodextrin capillary column in order to determine the ee of the products. ${ }^{24}$

\section{Acknowledgements}

The authors thank the FCT (projects Pest-C/QUI/UI0313/2011 and PEstOE/QUI/UI0313/2014), FEDER, COMPETE and QREN for financial support (including Dora Costa grant UI0117/QUI/UI0113/2014) and the UC-NMR facility for NMR spectroscopic data (FCT, grant numbers REEQ/481/QUI/2006, RECI/QEQQFI/0168/2012, CENTRO-07-CT62-FEDER-002012 and RNRMN, FEDER and COMPETE).

\section{References}

1. Pu, L.; Yu, H. B. Chem. Rev. 2001, 101, 757.

2. Lin, G.; Li, Y.; Chan, A. S. C. Principles and Applications of Asymmetric Synthesis; John Wiley \& Sons, Inc.: New York, 2001.

3. Naganawa, Y.; Namba, T.; Aoyama, T.; Shoji, K.; Nishiyama, H. Chem. Commun. 2014, 50, 13224.

4. Karabuga, S.; Karakaya, I.; Ulukanli, S. Tetrahedron Asymmetry 2014, 25, 851. 
5. Zhang, W.; Tang, R.; Yu, H.; Gao, S. Appl. Organomet. Chem. 2014, 28, 545.

6. Noyri, R.; Kitamura, M. Angew. Chem., Int. Ed. 1991, 30, 49.

7. Soai, K.; Niwa, S. Chem. Rev. 1992, 92, 833.

8. Gök, Y.; Küloğlu, S.; Gök, H. Z.; Kekeç, L. Appl. Organomet. Chem. 2014, 28, 835.

9. Jarzyński, S.; Leśniak, S.; Pieczonka, A. M.; Rachwalski, M. Tetrahedron: Asymmetry 2015, 26, 35.

10. De Las Casas Engel, T.; Maroto, B. L.; De La Moya Cerero, S. Eur. J. Org. Chem. 2010, 1717.

11. Aga, M. A.; Kumar, B.; Rouf, A.; Shah, B. A.; Taneja, S. C. Tetrahedron Lett. 2014, 55, 2639.

12. Kang, S. Y.; Park, Y. S. Eur. J. Org. Chem. 2012, 1703.

13. Zanardi, M. M.; Suárez, A. G. Tetrahedron Lett. 2015, 56, 3762.

14. Asami, M.; Miyairi, N.; Sasahara, Y.; Ichikawa, K. I.; Hosoda, N.; Ito, S. Tetrahedron 2015, 71, 6796.

15. Asami, M.; Hasome, A.; Yachi, N.; Hosoda, N.; Yamaguchi, Y.; Ito, S. Tetrahedron: Asymmetry 2016, 27, 322.

16. Nottingham, C.; Benson, R.; Muller-Bunz, H.; Guiry, P. J. J. Org. Chem. 2015, 80, 10163.

17. Zanardi, M. M.; Botta, M. C.; Suárez, A. G. Tetrahedron Lett. 2014, 55, 5832.

18. Kim, S.-H.; Ahn, S.-J.; Chung, S.-T.; Jin, M. J. J. Ind. Eng. Chem. 1997, 3, 37.

19. Meng, Q. L.; Li, Y. L.; He, Y.; Guan, Y. D. Chin. Chem. Lett. 2000, 11, 761.

20. Meng, Q.; Li, Y.; He, Y.; Guan, Y. Tetrahedron: Asymmetry 2000, 11, 4255.

21. Jin, M. J.; Kim, S. H. Bull. Korean Chem. Soc. 2002, 23, 509.

22. Huang, H. L.; Lin, Y. C.; Chen, S. F.; Wang, C. L. J.; Liu, L. T. Tetrahedron Asymmetry 1996, 7, 3067.

23. Calmes, M.; Escale, F.; Paolini, F. Tetrahedon: Asymmetry 1997, 8, 3691.

24. Murtinho, D.; Elisa Silva Serra, M.; Rocha Gonsalves, A. M. d'A. Tetrahedron: Asymmetry 2010, 21, 62.

25. Serra, M.; Murtinho, D.; Goth, A. Chirality 2010, 22, 425.

26. Rocha Gonsalves, A. M. d'A.; Serra, M. E. S.; Murtinho, D.; Silva, V. F.; Matos Beja, A.; Paixão, J.; Ramos Silva, M.; Alte da Veiga, L. J. Mol. Catal. A Chem. 2003, 195, 1.

27. Rocha Gonsalves, A. M. d'A.; Elisa S. Serra, M.; Murtinho, D. J. Mol. Catal. A Chem. 2006, 250, 104.

28. Braga, A. L.; Milani, P.; Vargas, F.; Paixão, M. W.; Sehnem, J. A. Tetrahedron: Asymmetry 2006, 17, 2793.

29. Webb, R. G.; Haskell, M. W.; Stammer, C. H. J. Org. Chem. 1969, 34, 576.

30. Sutcliffe, O. B.; Storr, R. C.; Gilchrist, T. L.; Rafferty, P. J. Chem. Soc. Perkin Trans. 1 2001, 1795.

31. Talley, J. M.; Cerda, B. A.; Ohanessian, G.; Wesdemiotis, C. Chem. - Eur. J. 2002, 8, 1377.

32. Lee, W.-Z.; Chiang, C.-W.; Kulkarni, G. M.; Kuo, T.-S. J. Chin. Chem. Soc. 2013, 60, 245.

33. Wróbel, Z.; Justyniak, I.; Dranka, I.; Lewiński, J. Dalton Trans. 2016, 45 (17), 7240. 
34. Benedini, F.; Ferrario, F.; Sala, A.; Sala, L.; Soresinetti, P. A. J. Heterocycl. Chem. 1994, 31, 1343.

35. Szilágyi, L.; Gyorgydeák, Z. J. Am. Chem. Soc. 1979, 101, 427.

36. Brunner, H.; Becker, R.; Riepl, G. Organometallics 1984, 3, 1354.

37. Bolm, C.; Muniz, K.; Hildebrand, J. P. Org. Lett. 1999, 1, 491.

38. Pinho e Melo, T. M. V. D.; Santos, C. I. A.; Rocha Gonsalves, A. M. d'A.; Paixão, J. A.; Beja, A. M. Tetrahedron 2004, 60, 3949.

39. Dickschat, J. S.; Wenzel, S. C.; Bode, H. B.; Muller, R.; Schulz, S. ChemBioChem 2004, 5, 778.

40. Bentleya, R.; Cook, H.; Elvidge, J. A.; Shaw, G. J. Chem. Soc. 1949, 2351.

41. Cook, H.; Heilbron, L. M. in The Chemistry of Penicillin; Cook, H., Johnson, J. R., Robinson, R., Eds.;

Princeton University Press: Princeton, 1949; pp 921-972. 


\section{SCHEMES}

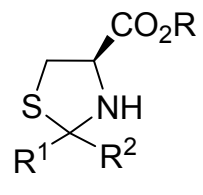

1

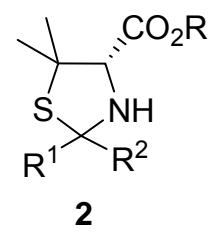

Scheme 1

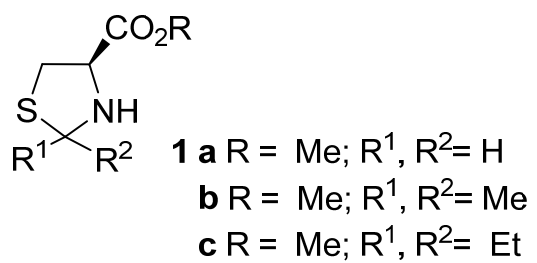

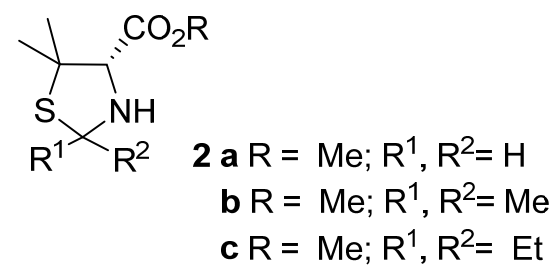

Scheme 2

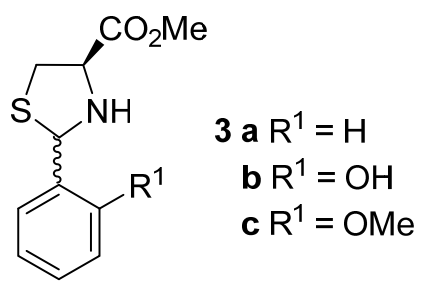

Scheme 3

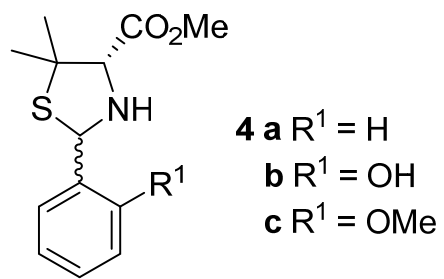




\section{TABLES}

Table 1. Enantioselective alkylation of benzaldehyde in the presence of chiral thiazolidines 1-2.

\begin{tabular}{|c|c|c|c|c|}
\hline Entry & Ligand & $\begin{array}{c}\text { Conversion } \\
(\%)^{\mathrm{b}}\end{array}$ & $\begin{array}{c}\text { 1-phenyl-1-propanol } \\
(\%)^{\mathrm{b}}\end{array}$ & $\begin{array}{c}e e \\
(\%)^{\mathrm{c}}\end{array}$ \\
\hline 1 & $1 a$ & 99 & 96 & $67(S)$ \\
\hline 2 & $1 b$ & 95 & 96 & $83(S)$ \\
\hline 3 & $1 c$ & 99 & 99 & $89(S)$ \\
\hline 4 & $2 a$ & 99 & 98 & $93(R)$ \\
\hline 5 & $2 b$ & 99 & 99 & $92(R)$ \\
\hline 6 & $2 c$ & 99 & 99 & $94(R)$ \\
\hline
\end{tabular}

${ }^{a}$ Reactions conditions: cyclohexane $(4 \mathrm{~mL})$, chiral ligand $(0.15$ $\mathrm{mmol})$, benzaldehyde $(1 \mathrm{mmol})$, diethylzinc solution $1 \mathrm{M}$ in hexane (2 mmol), $24 \mathrm{~h}$, room temperature. 'Determined by GC. 'Determined by GC on a chiral column; the major enantiomer is indicated in parenthesis.

Table 2. Enantioselective alkylation of benzaldehyde in the presence of chiral thiazolidines 3-4. ${ }^{a}$

\begin{tabular}{ccccc}
\hline Entry & Ligand & $\begin{array}{c}\text { Conversion } \\
(\%)^{b}\end{array}$ & $\begin{array}{c}\text { 1-phenyl-1-propanol } \\
(\%)^{b}\end{array}$ & $\begin{array}{c}\text { ee } \\
(\%)^{\mathrm{c}}\end{array}$ \\
\hline 1 & 3a & 92 & 98 & $75(S)$ \\
2 & 3b & 77 & 78 & $10(S)$ \\
3 & 3c & 91 & 95 & $57(S)$ \\
4 & 4a & 95 & 97 & $87(R)$ \\
5 & 4b & 92 & 90 & $11(R)$ \\
6 & 4c & $>99$ & 99 & $84(R)$ \\
\hline
\end{tabular}

${ }^{a}$ Reactions conditions: cyclohexane $(4 \mathrm{~mL})$, chiral ligand $(0.15$ $\mathrm{mmol})$, benzaldehyde $(1 \mathrm{mmol})$, diethylzinc solution $1 \mathrm{M}$ in hexane (2 mmol), $24 \mathrm{~h}$, room temperature. 'Determined by GC. 'Determined by GC on a chiral column; the major enantiomer is indicated in parenthesis. 
Table 3. Enantioselective alkylation of aromatic aldehydes in the presence of chiral thiazolidine $\mathbf{2} \mathbf{a}{ }^{a}$

\begin{tabular}{cccc}
\hline Entry & Aldehyde & $\begin{array}{c}\text { Conversion } \\
(\%)^{\mathrm{b}}\end{array}$ & $\begin{array}{c}\text { ee } \\
(\%)^{\mathrm{c}}\end{array}$ \\
\hline 1 & benzaldehyde & $>99$ & $95(R)$ \\
2 & o-methylbenzaldehyde & $>99$ & $89(R)$ \\
3 & $p$-methylbenzaldehyde & $>99$ & $95(R)$ \\
4 & o-anisaldehyde & $>99$ & $98(R)$ \\
5 & m-anisaldehyde & $>99$ & $>99(R)$ \\
6 & $p$-anisaldehyde & 97 & $>99(R)$ \\
7 & o-chlorobenzaldehyde & $>99$ & $86(R)$ \\
8 & $p$-chlorobenzaldehyde & $>99$ & $91(R)$ \\
9 & 1-naphthaldehyde & 99 & $97(R)$ \\
\hline
\end{tabular}

${ }^{a}$ Reactions conditions: cyclohexane $(4 \mathrm{~mL})$, chiral ligand $(0.15 \mathrm{mmol})$, aldehyde $(1 \mathrm{mmol})$, diethylzinc solution $1 \mathrm{M}$ in hexane $(2 \mathrm{mmol}), 24 \mathrm{~h}$, room temperature. ${ }^{\mathrm{b}}$ Determined by GC. 'Determined by GC on a chiral column; the major enantiomer is indicated in parenthesis.

Table 4. Enantioselective alkylation of cinnamaldehyde and furfural in the presence of chiral thiazolidine $2 a^{a}{ }^{a}$

\begin{tabular}{|c|c|c|c|c|}
\hline Entry & Aldehyde & Temperature & $\begin{array}{c}\text { Conversion } \\
(\%)^{b}\end{array}$ & $\begin{array}{l}e e \\
(\%)^{c}\end{array}$ \\
\hline 1 & \multirow{3}{*}{$\approx \mathrm{CHO}$} & rt & 99 & 47 \\
\hline 2 & & $0^{\circ} \mathrm{C}$ & $>99$ & 56 \\
\hline 3 & & $-10^{\circ} \mathrm{C}$ & 96 & 56 \\
\hline 4 & \multirow{2}{*}{ "I- $\mathrm{CHO}$} & $\mathrm{rt}$ & $>99$ & 56 \\
\hline 5 & & $0^{\circ} \mathrm{C}$ & $>99$ & 60 \\
\hline 6 & $\mathrm{CHO}$ & $\mathrm{rt}$ & 30 & 24 \\
\hline 7 & $\sim_{\mathrm{CHO}}$ & $\mathrm{rt}$ & 99 & $80^{d}$ \\
\hline $\begin{array}{l}{ }^{2} \text { Reacti } \\
\text { aldehyc } \\
\text { }{ }^{\circ} \text { Deterr } \\
\text { by pola }\end{array}$ & $\begin{array}{l}\text { onditions: cyclo } \\
\mathrm{mmol} \text { ), diethylz } \\
\text { by GC. 'Determ } \\
\text { ry. }\end{array}$ & $\begin{array}{l}\text { ane }(4 \mathrm{~mL}), \mathrm{ch} \\
\text { solution } 1 \mathrm{M} \text { in } \\
\text { by } \mathrm{GC} \text { on a ch }\end{array}$ & $\begin{array}{l}\text { al ligand }(0.15 \\
\text { exane }(2 \mathrm{mmc} \\
\text { al column. }{ }^{d} \text { Det }\end{array}$ & $\begin{array}{r}\mathrm{nmol}), \\
24 \mathrm{~h} . \\
\text { mined }\end{array}$ \\
\hline
\end{tabular}

